\title{
Impact of BYOD on organizational commitment: An empirical investigation
}

\author{
Melina Seedoyal Doargajudhur, Peter Dell
}

\section{Introduction}

In the past two decades the IT industry has increasingly focused on customers, and the drive is now more towards a consumer-driven bottom-up approach as compared to the traditional top-down IT innovation (Leclercq-Vandelannoitte, 2015; Weeger et al., 2015). The availability of consumer tools such as mobile devices and tablet computers and the significant drop in prices for facilities such as voice/data communication provided by mobile networks has led to the widespread diffusion of mobile devices for personal usage. Consequently, individuals are more and more accustomed to the convenience and benefits obtained from the use of personal mobile devices to such an extent that they are willing to bring privatelyowned devices into their professional spheres to fulfil business tasks, thus giving rise to the BYOD (Bring Your Own Device) trend (Köffer et al., 2014). Harris et al. (2012) cite statistics that as early as 2011, 23\% of employees were already routinely using BYOD, and a further $29 \%$ at least once a week, and at approximately the same time $77 \%$ of CIOs had plans to provide employees with mobile access to company data and applications (Disterer and Kleiner, 2013). BYOD uptake by organisations has been reportedly as high as $80 \%$ in various countries (Spain, Brazil, Malaysia and Singapore), and $85 \%$ of individuals in Malaysia also reportedly use personal devices in the workplace (Eslahi et al., 2014).

This is at least partly because users are more comfortable and familiar with their consumer tools and increasingly wish to use these in their professional environment so that their daily work tasks are completed more rapidly and efficiently (Steelman et al., 2016). The demand for utilizing privately owned technologies in their corporate environment is expected to rise in the future as individuals are encouraged more and more to use their personal devices in their professional spheres (Weeger et al., 2015).

Although there is strong demand from employees to be able to bring their own devices into the workplace, BYOD is not without risk (Harris et al., 2012), with some referring to BYOD as "Bring Your Own Danger" and even predicting "IT anarchy" (Disterer and Kleiner, 2013). The area of risk that has perhaps received the greatest attention is security (Niehaves et al., 2012; Disterer and Kleiner, 2013). BYOD can pose a threat to the confidentiality, integrity and authenticity of the organization's data (Disterer and Kleiner, 2013) and although these threats are recognized by organizations they are often not recognized or responded 
to by end-users (Seigneur et al., 2013), and organizations sometimes struggle to establish effective guidelines for BYOD security (Niehaves et al., 2012).

In addition to security risks, BYOD can also pose legal and regulatory challenges. Inevitably there will be different rules in different countries or jurisdictions (Harris et al., 2012), in particular in relation to aspects such as privacy and data protection requirements, and this may pose compliance challenges when using BYOD. BYOD can even pose technical challenges such as reliability and performance, and also pose challenges to data accuracy (Harris et al., 2012), such as when data stored on mobile devices becomes outof-date due to intermittent mobile connectivity (Weiß and Leimeister, 2012).

Nevertheless, the risks posed by BYOD can be mitigated by finding a "manageable compromise" between authoritarian and laissez-faire approaches (Harris et al., 2012). Firms are therefore increasingly allowing their employees to use their privately owned technologies to perform their business activities and due to the rapid growth of reliable mobile technologies (Chou et al., 2017), BYOD has become a feasible strategy to promote employees' well-being in the workplace.

Although the BYOD trend continues to grow in popularity and has been frequently discussed in practice, little scientific research has been conducted into the phenomenon (Köffer et al., 2014; Weeger et al., 2015). Few insights have been provided into the consequences of BYOD adoption, particularly its impact on work performance, and prior Information Systems (IS) research has not had much focus on theory development (Niehaves et al., 2012). Indeed BYOD demands further extensive work (Niehaves et al., 2012; Köffer et al., 2014), including empirically examining the consequences of BYOD adoption (Weeger et al., 2015). We note a rare exception to date is Giddens and Tripp's (2014) proposed theoretical model to examine the effect of BYOD on job satisfaction and job performance based on the Social Cognitive Theory and the Job Characteristics Model; however this model was not empirically tested. In addition, Niehaves et al. (2012); Niehaves et al. (2013) proposed a model based on qualitative findings to test the effect of BYOD on job performance by utilizing the cognitive model of stress and the self-determination theory and affirmed that perceived competence, increased perceived workload and perceived autonomy all affect the impact that BYOD has on employees. These authors suggested that their framework is open to extension and that the effect of BYOD on job performance has not been treated exhaustively. They also proposed that further work should be done on the effects of BYOD to determine if employees are more productive (Köffer et al., 2014; Ortbach, 2015).

In addition, for decades, ongoing debates have focused on the question: What appropriate Information Technology should an organization utilize to maximize performance? Organizations sometimes do not consider which IT would be more effective and result in greater job performance and satisfaction of their employees (Köffer et al., 2014). These debates revolve around who should decide about the selection, 
adoption and usage of the IT tools to be used within the organizations: the IT department, or the users who are nearer to the problems (Brown and Grant, 2005).

To respond to these calls for further research from the IS field, researchers are encouraged to investigate the consequences of BYOD adoption. Therefore, this paper provides insights into the impact of BYOD on job satisfaction, job performance and organizational commitment. To the authors' knowledge, organizational commitment has not been examined in prior BYOD research and no prior model has incorporated these constructs in an integrated theoretical framework to determine the impact that BYOD has on these outcomes. Moreover, an issue of growing prominence in contemporary organizations is the need to have a motivated, inspired, satisfied and committed workforce who are able to go "the extra mile" (Bakker and Demerouti, 2008). For this reason, the study of employee well-being (through job satisfaction), performance and commitment has become extremely pertinent among practitioners and researchers. By examining the consequences of BYOD adoption, this study contributes to the limited literature on this phenomenon and provides deeper insights into the factors enabling employees to flourish at work, both theoretically and empirically.

Unlike prior BYOD studies, this study utilizes the Job Demands-Resources (JD-R) model and TaskTechnology Fit Theory as its theoretical lenses; the relevance of these theoretical frameworks to the impact of BYOD on employees' organizational commitment is explained in the following section.

\section{Theoretical Foundation}

\section{Job Demands-Resources Theory}

The Job Demands-Resources (JD-R) Model Demerouti et al. (2001) has recently gained popularity among researchers and is a comprehensive and parsimonious model for exploring and conceptualizing occupational well-being, engagement, and burnout (Schaufeli and Bakker, 2004). Bakker and Demerouti (2007) claim that the JD-R model offers a flexible approach since the model can be applied to any work environment and can also be tailored for any specific occupation. Although every profession may have its own job characteristics, the assumption lying at the heart of the JD-R model is that these job features are classified into two general categories: job demands and job resources (Bakker et al., 2010; Bakker and Demerouti, 2014; Bakker et al., 2003; Bakker et al., 2007; Bakker et al., 2010; Boyd et al., 2011; Clausen and Borg, 2011; Demerouti et al., 2001; Langelaan et al., 2006; Schaufeli and Bakker, 2004; Xanthopoulou et al., 2007; McGregor et al., 2016).

Job Demands are those social, organizational, physical or psychological aspects of the job which demand constant mental or physical effort and are consequently related to certain physiological or physiological costs (Demerouti et al., 2001). Examples include job insecurity, high work pressure, work overload, 
interpersonal conflict, heavy lifting, and emotionally demanding interactions with clients. Additional effort is required to achieve work objectives and avoid decreasing performance in the event that job demands are high (Schaufeli and Taris, 2014), and as a result, psychological and physical costs including irritability and fatigue are likely to arise. Employees are therefore advised to conduct less demanding tasks, take breaks or switch tasks in order to recover from mobilizing this additional effort.

In contrast, job resources are those physical, psychological, social, or organizational aspects of the job which help to fulfill these three functions: (a) achieving work goals; (b) encouraging personal development, learning and growth; and (c) reducing job demands and their associated psychological and physiological costs. Job resources are found at the organizational level, the social relation and interpersonal level, and finally at the task level (Bakker and Demerouti, 2007), and include examples such as social support, feedback, job control and job autonomy. Job resources are also significant in other ways beside helping to reduce work demands as they are considered to be the means for achieving or protecting other valued resources such as organizational commitment (Bakker and Demerouti, 2007; Bakker et al., 2010; Boyd et $a l ., 2011)$. This is congruent with the job characteristics model proposed by Hackman and Oldham (1980) which emphasizes that job resources such as task significance, feedback and job autonomy promote workrelated motivation and satisfaction at the task level.

Indeed, Bakker and Demerouti (2014) argue that it is possible to predict, explain and understand employee well-being and job performance through JD-R, and that the JD-R model has matured into a theory due to its utilization in several studies, new propositions and numerous meta-analyses.

Another premise of the JD-R theory is that the two categories of job features, job resources and job demands, trigger two independent processes, namely motivation and health. Being motivational in nature, job resources lead to work enjoyment, low cynicism, high work engagement and excellent performance. Bakker and Demerouti (2007) also emphasized on the motivational (intrinsic and extrinsic) nature of job resources where an intrinsic motivational role fosters employees' development, growth and learning while an extrinsic motivational role helps in attaining work objectives. In addition, job resources satisfy basic human needs including competence, autonomy and relatedness (Deci and Ryan, 1985). On the other hand, job demands are usually the greatest key predictors of repetitive strain injury, exhaustion, psychosomatic health complaints, and many other health problems. This is mainly due to jobs being poorly designed or chronic job demands such as work overload and emotional demands (Demerouti et al., 2001).

In this study, the job demand 'perceived workload' and the job resource 'perceived job autonomy' are included in the theoretical model as they are both relevant to BYOD. It is proposed that the job resource 'perceived job autonomy' interacts with the job demand 'perceived workload' in predicting positive work outcomes such as job satisfaction, job performance self-assessment and organizational commitment. The 
current study utilizes a heterogeneous sample and hypothesizes that perceived workload predicts job performance self-assessment, perceived job autonomy predicts employee well-being (through job satisfaction), job performance self-assessment and organizational commitment. Finally, it should also be noted that the present study does not consider negative outcomes like burnout, disengagement, exhaustion, among others as the focus is on positive work outcomes. This is congruent with other studies which also applied only job characteristics and work engagement (Bakker et al., 2007; Hakanen et al., 2005).

\section{Task-Technology Fit Model}

The Task-Technology Fit Model (TTFM) holds that a technology will impact positively on performance when its functions are matched with the requirements of the task (Goodhue and Thompson, 1995). This theory states that users must willingly accept and use the technology, that there must be a good fit between the task and the technology, and also between the users and the technology (Lee et al., 2007; Tarhini et al., 2016).

The TTFM consists of four key dimensions: Technology features, Task features, TTF, and the impacts on performance. The first two constructs, technology features and task features, together affect the third dimension, TTF. This in turn has an impact on the outcome, that is, either performance or utilization. Technology features relate to features of the devices or tools which individuals use to perform their tasks and in the IS field, technology implies all the hardware, software, data resources, and any other support facilities such as help-lines and training which support people in doing their work (Goodhue and Thompson, 1995). The second attribute, tasks, refers to the activities of converting inputs into outputs by people so that they can satisfy their information needs. Finally, the main construct of the Task-Technology-Fit Model is the TTF. Goodhue and Thompson (1995, p. 216) define TTF as "the degree to which a technology assists an individual in performing his or her portfolio of tasks". The core of this construct is that information systems will only have a positive impact on individual performance if the technology used effectively supports the work requirements (Taegoo et al., 2010).

Goodhue and Thompson (1995) have used this model to analyze and explain the success of IS and its impact on individual performance, and proposed a model known as the technology-to-performance chain in which dimensions such as tasks, users and IT explain the IS use and performance of individuals. Several IS studies have demonstrated the usefulness of this model from various perspectives including studies of improved user utilization (Venkatesh et al., 2003; Kim and Malhotra, 2005), and improved performance (Carswell et al., 2000; Goodhue et al., 2000).

The research model in the present study includes the TTF construct. Empirical evidence demonstrates that people will only accept and use technology if it fits their needs and subsequently, improves their performance (Junglas and Watson, 2008; Gebauer and Ginsburg, 2009). Users will complete their business 
tasks by utilizing their privately-owned technologies only if these fit their needs. Hence, in addition to the JD-R model, the TTFM is also adopted in this study since this theory is a powerful model that helps to understand the adoption of an innovative information technology in a specific context (Benbasat and Barki, 2007).

\section{Research Model and Hypotheses}

Figure 1 presents the research model, which theorizes that BYOD leads to increases in perceived job autonomy, perceived workload and improved task-technology fit, resulting in increased job performance self-assessment, job satisfaction and organizational commitment.

\section{Figure 1. The research model}

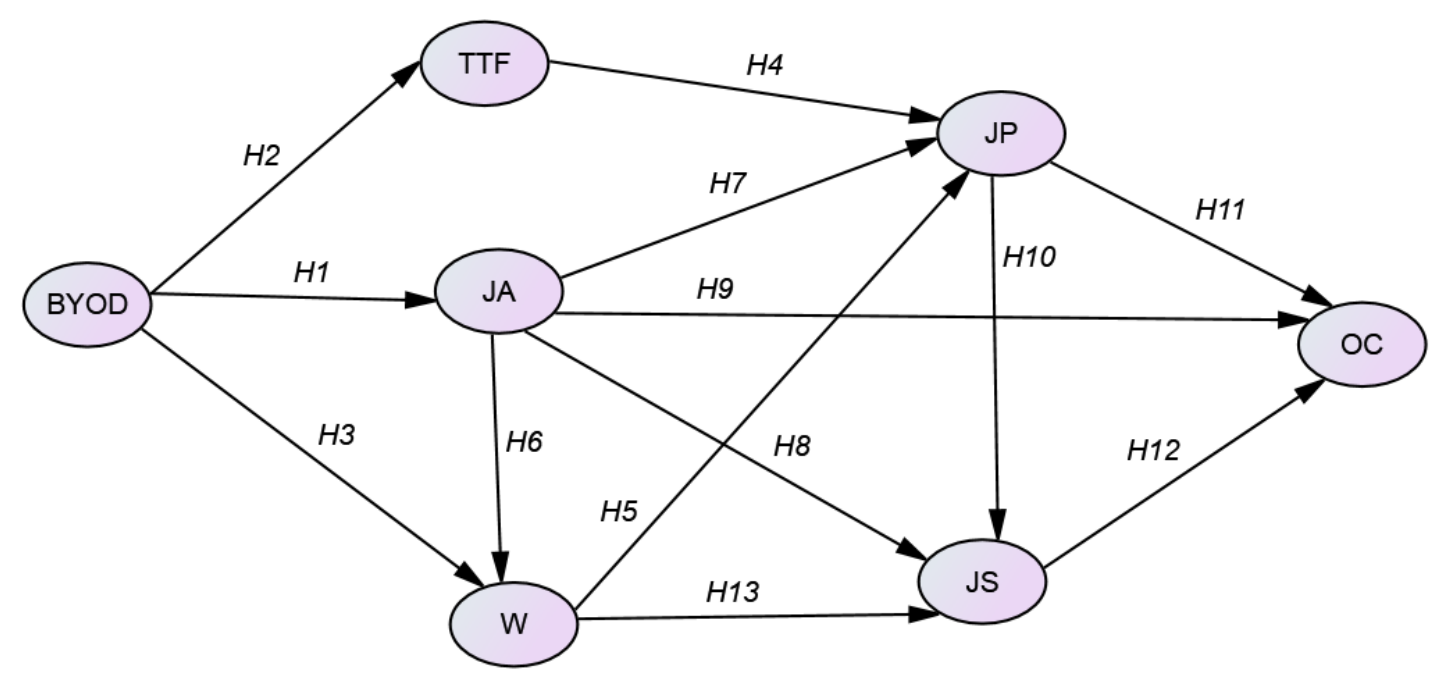

\section{Notes:}

BYOD: Bring Your Own Device; TTF: Task-Technology Fit; JA: Perceived Job Autonomy; W: Perceived Workload; JS: Job Satisfaction; JP: Job Performance Self-Assessment; OC: Organizational Commitment. 
BYOD adoption: relationships with perceived job autonomy, task-technology fit and perceived workload

BYOD refers to the use of personal laptops, smartphones, tablets and any other private tool to conduct work-related activities (Niehaves et al., 2013). Also known as IT consumerization (Köffer et al., 2014) and 'Consumer IT used as corporate IT' (Hudson and Grant, 2013), BYOD is the adoption and use of private consumer technologies and applications in the workplace. For the purpose of this study, BYOD is defined as privately owned consumer technologies, including laptops, smartphones, tablets and other devices, and their associated software, which is co-used for work-related purposes. This phenomenon has been discussed over several years (Moschella et al., 2004) and is considered to be a highly significant topic in practice (Niehaves et al., 2012; Köffer et al., 2014; Ortbach, 2015), thus causing a remarkable impact on how work is conducted. It has also gained much popularity in both academic as well as practitioner fields (Niehaves et al., 2012; Niehaves et al., 2013; Ortbach et al., 2013; Ortbach et al., 2013; Köffer et al., 2014; Ortbach et al., 2014; Ortbach, 2015).

Perceived job autonomy refers to "the degree to which a worker has control over how and when work is done" DeVaro et al. (2007, p. 992). Morris and Venkatesh (2010) suggested that technology usage has an impact on employees' autonomy, and is likely that workers who are given the freedom to choose the tools they use for work purposes themselves would perceive a greater sense of autonomy than workers who are not given this choice, and indeed Niehaves et al. $(2012,2013)$ found that employees feel a greater sense of autonomy when utilizing their personal devices for work purposes. Similarly, (Harris et al., 2012) report that employees value the independence that comes from being able to choose their own tools. Therefore, the following hypothesis is proposed:

H1: BYOD is positively associated with perceived job autonomy.

Goodhue and Thompson (1995) argue that people complete tasks more effectively when the technology used is willingly accepted and fits well with the users and the assigned tasks. The task-technology fit construct refers to the relationship between the abilities of the individual, the requirements of the tasks, and the functions of the device and its software. Employees are more likely to use their own device to complete work-related tasks if they believe that there is a better fit between their chosen device, the work to be completed and their skills. Hence, the following hypothesis is developed:

H2: BYOD is positively associated with Task-Technology Fit.

Lee and Ashforth (1996) describe perceived workload as the perceived pressure that an employee experiences while completing work tasks and consider it as one of the key demands of work. Niehaves $e t$ al. (2013); Niehaves et al. (2012) reported that employees perceive that they have more work to do when using their personal devices for work purposes. Hence, the following hypothesis is proposed: 
H3: BYOD is positively associated with perceived workload.

According to Goodhue and Thompson (1995), an individual will perform better if there is a high level of task-technology fit and if the person is satisfied with the technology. Indeed, a good fit between the technology, the task, and the user promotes users' willingness to use that technology to enhance their work performance (Lee et al. 2007). In this study, employees' adoption of BYOD implies a good TTF, thus leading to their readiness to use their devices for better work performance, which is congruent with prior research (Junglas and Watson, 2008; Gebauer and Ginsburg, 2009). Hence, the following hypothesis is proposed:

H4. TTF is positively associated with job performance self-assessment.

\section{Perceived workload and job performance}

Job performance is conceptualized as an individual's controlled behaviors and actions which help in contributing towards the objectives of the organization (Rotundo and Sackett, 2002). Motowildo et al. (1997, p. 72) define performance as the "behavior with an evaluative component, behavior that can be evaluated as positive or negative for individual or organizational effectiveness". For the purpose of this study, job performance is defined as an employee's perception of the quality of work, effectiveness and overall work conducted. Bakker et al. (2004) reported that increased perceived workload can lead to greater job performance, a relationship which has also been identified qualitatively (Niehaves et al., 2013). Based on this discussion, the following hypothesis is proposed:

H5. Perceived workload is positively associated with job performance self-assessment.

\section{Perceived job autonomy and perceived workload}

Being autonomous allows workers to be flexible with how, where and when they do their work, including working at times or in places they otherwise would not. Facilitating workers to continue working after hours, at home or 'on the road', could increase their perceptions of their workload (and indeed the amount of work they actually complete). This reasoning is consistent with (Moore, 2000), who found a significant correlation between autonomy and perceived workload, and with (Ahuja et al., 2007) who found that more autonomy was associated with a lower perception of being overworked. This is consistent with the JD-R's central theory that job resources such as autonomy help workers manage the demands of their job, and hence in this study the following hypothesis is developed:

H6. Perceived job autonomy is positively associated with perceived workload. 


\section{Perceived job autonomy and job performance}

Employees with a high sense of autonomy will experience higher job satisfaction and will perform better in their work-related tasks while those with a low sense of autonomy will experience poorer performance and are more prone to work exhaustion (Hackman and Oldham, 1980). The JD-R model also contends that job autonomy can lead to greater job performance when employees are given freedom and independence in how they conduct their work (Bakker et al., 2004). However, there are mixed findings in the literature relating to the relationship between job autonomy and behavioral responses such as work performance (DeVaro et al., 2007; Hackman and Oldham, 1976; Hackman et al., 1978; Kemp and Cook, 1983; Parker et al., 2001; Umstot et al., 1976). In their findings, Dodd and Ganster (1996); Shirom et al. (2006) reported that those who have the freedom and independence to conduct their work are more likely to benefit from greater job performance. Therefore, based on the preceding empirical and theoretical discussion, the following hypothesis is proposed:

H7. Perceived job autonomy is positively associated with job performance self-assessment.

\section{Perceived job autonomy and job satisfaction}

In contrast to the inconsistent results between job autonomy and job performance, the literature has consistent support for the relationship between job autonomy and employees' job satisfaction (Becherer $e t$ al., 1982; Teas, 1981; Dubinsky and Skinner, 1984; Hackman and Oldham, 1976; DeVaro et al., 2007). The JD-R model also predicts that employees derive higher job satisfaction when they are autonomous and can make their own decisions about how to go about with their work (Yeh, 2015; DeVaro et al., 2007; Dodd and Ganster, 1996; Schulz et al., 1995; Spector, 1986; Chen, 2008). Therefore, the following hypothesis is proposed:

H8. Perceived job autonomy is positively associated with job satisfaction.

\section{Perceived job autonomy and organizational commitment}

Organizational commitment is another construct which has gained a lot of attention in organizational research due to its relationship with work outcomes such as job performance, job satisfaction, work motivation, job involvement and turnover, among others (Michaels and Spector, 1982; Farrell and Stamm, 1988; Mathieu and Zajac, 1990; Tett and Meyer, 1993; Eby et al., 1999a). Organizational commitment refers to the extent to which a person identifies himself with and is engaged in the organization (Mowday et al., 1982), and has three dimensions: normative commitment (when employees strongly believe and accept the goals and values of the organization), affective commitment (when employees agree to put in effort on behalf of their organization); and continuance commitment (when employees strongly aspire to remain part of the organization) (Mowday et al., 1979). Employees with a strong affective commitment 
have a strong emotional attachment to their organizations (Allen and Meyer, 1990; Klein et al., 2012), and this is the most relevant dimension of organizational commitment in the context of the present study. The JD-R model postulates that job autonomy is likely to influence employees' commitment towards their organization (Bakker et al., 2003; Bakker et al., 2010), and there is support in the literature for the positive relationship between job autonomy and organizational commitment (Eby et al., 1999; Wall et al., 1986; Ahuja et al., 2006; Spector, 1986; Park and Searcy, 2012). Based on this discussion, the following hypothesis is proposed:

H9. Perceived job autonomy is positively associated with organizational commitment.

\section{Job performance and job satisfaction}

Lawler and Porter (1967) conclude that performance has a causal impact on satisfaction due to the intrinsic and extrinsic rewards that come from high performance, and that intrinsic rewards themselves are often overlooked despite the fact that, often, "good performance is rewarding in and of itself". In other words, good performance can be intrinsically satisfying. The theory that performance leads to satisfaction has also been supported in many other studies, including Locke (1970), Siegel and Bowen (1971), Bagozzi (1980), Stumpf and Hartman (1984), Darden et al. (1989) and MacKenzie et al. (1998).

It is noted that the relationship between job performance and job satisfaction has been extensively investigated in a great many studies since at least the 1950s and has sometimes been described as the "Holy Grail" of industrial psychology (Judge et al., 2001). However, on the basis of the evidence above we predict a causal relationship from performance to satisfaction, as in $\mathrm{H} 10$ below:

H10. Job performance self-assessment is positively associated with job satisfaction.

\section{Job performance and organizational commitment}

Employees feel more committed towards their organization when they perform well in their job. The flexibility of the JD-R theory lends it to investigating questions relating to employees' well-being as well as factors such as job performance and organizational commitment (Bakker and Demerouti, 2014; Bakker and Demerouti, 2007). In the current study, the JD-R model has been applied to incorporate organizational commitment as the dependent variable. Based on this discussion, the following hypothesis is developed:

H11. Job performance self-assessment is positively associated with organizational commitment.

\section{Job satisfaction and organizational commitment}

Employees feel more committed towards their organization when they are satisfied with their job (Iverson and Roy, 1994; Wallace, 1995; Gaertner, 2000; Petrides and Faunham, 2006; Naderi Anari, 2012; Fu and Deshpande, 2014), and hence, the following hypothesis is proposed: 
H12. Job satisfaction is positively associated with organizational commitment.

\section{Perceived workload and job satisfaction}

According to Kunte et al. (2017), work overload is an antecedent of job dissatisfaction. De Cuyper and De Witte (2006) and Kunte et al. (2017) argue that it is rather surprising that not enough empirical work has been carried out to investigate the causal relationship between work overload and job satisfaction. Therefore, in response to this shortage of empirical studies, the present study examines the role of not only job resources (job autonomy) but also perceived workload (job demands) in explaining its relationship with job satisfaction. Accordingly, the following hypothesis is proposed:

H13: Perceived workload is negatively associated with job satisfaction.

\section{Research methodology}

\section{Sample and procedure}

The present study employed a quantitative research approach to test the proposed research model. Data collection targeted full-time knowledge workers in Mauritian enterprises. Respondents were asked to complete a survey questionnaire and participation was voluntary. Participants were briefed on the aim of this study and on average, each one took around $10 \mathrm{~min}$ to complete the questionnaire. 402 responses were obtained and two invalid questionnaires were excluded from the analysis because they contained missing responses, so to avoid biased statistical results, these were eliminated for further analysis. Consequently, the final sample contained 400 respondents, thus satisfying the minimum sample requirement of 200 which is recommended for the effective use of structural equation modeling (Anderson and Gerbing, 1988). As

shown in Table I, the gender split was $51.3 \%$ males and $48.3 \%$ females, with age range varied from 15 to above 65 years old. The sample was dominated by respondents from medium enterprises (43.8\%), followed by those in small enterprises (38.3\%), and finally by large enterprises (18\%). 
Table I. Demographic profile

\begin{tabular}{lll}
\hline Demographics & Frequency & $\%$ \\
\hline Gender & 205 & 51.3 \\
Male & 193 & 48.3 \\
Female & & \\
& & \\
Age & 79 & 19.8 \\
$15-24$ & 148 & 37 \\
$25-34$ & 108 & 27 \\
$35-44$ & 31 & 7.8 \\
$45-54$ & 26 & 6.5 \\
$55-64$ & 4 & 1 \\
65 years and above & & \\
& & \\
Type of organization & 153 & 38.3 \\
Small & 175 & 43.8 \\
Medium & 72 & 18 \\
Large & &
\end{tabular}

\section{Measurement of constructs}

All measurement items for the current study were adapted from prior empirical studies related to JD-R, TTF and BYOD in order to ensure the reliability and validity of those items. A seven-point Likert scale with 'strongly disagree' at the low end and 'strongly agree' at the high end of the scale was used to measure the items relating to each construct within the research model. BYOD was measured using three items borrowed from Köffer et al. (2015) where respondents were asked about the extent to which they use their personal devices for work purposes on a scale where 1 represented 'to the least extent possible' and 7 'to the greatest extent possible'. Four items to measure perceived job autonomy were adopted from McKnight et al. (2009), Morris and Venkatesh (2010) and Tripp et al. (2016) while three items were taken from Larsen et al. (2009) and Goodhue and Thompson (1995) to measure task-technology fit. Perceived workload was 
measured by four items adopted from Bakker and Demerouti (2014). Job satisfaction was measured using three items borrowed from Keaveney and Nelson (1993), McKnight et al. (2009), Morris and Venkatesh (2010), Fast et al. (2014) and Tripp et al. (2016). In addition, four items were used to measure job performance and these were borrowed from Krishnan et al. (2002) and Lin and Huang (2008) while organizational commitment was measured using four items adopted from Ahuja and Thatcher (2005) and Tsui et al. (1997). Demographic aspects such as gender, age and type of organization were measured using nominal scales.

Prior to further study, we conducted a pilot test with 30 Mauritian knowledge-workers to modify and revise the indicators, in order to establish content validity and reliability. One of the BYOD indicators was modified based on the pilot-test results.

\section{Analysis and findings}

\section{Data analysis}

As recommended by Anderson and Gerbing (1988), this study employed a two-step method SEM (Structural Equation Modelling) approach. First, Confirmatory Factor Analysis (CFA) with maximum likelihood estimation using AMOS version 22 was used to develop the measurement model. Second, in order to explore the causal relationships among the constructs, the structural model for the proposed model was tested using SEM.

The authors first evaluated and re-specified the measurement model so that further measurement examination could be carried out. All the unidimensional constructs were paired with one another and the initial CFA was run. This was done by checking if a particular measure has large standardized residuals, and subsequently, those items were dropped to check if this resulted in an improved model fit. This resulted in deletion of three items and the model was reevaluated. After running this process, the remaining items are presented in Table III.

\section{Common method bias}

Given that this study collected data through the same method, self-administered questionnaires, at a single point in time, common method variance may introduce bias to the relationships among the constructs which may be a concern for this study, thus affecting the empirical results (Podsakoff et al., 2003). We subsequently employed the Common Latent Factor approach to test for Common Method Bias. A CFA was run with all the items presented in Table III, loading on a single common factor. This was followed by performing a chi-square difference test to compare the results of the CFA for the proposed measurement model with the common factor model. The results indicated that the proposed measurement model (Chisquare $\chi^{2}(299.44)=126$, that is, $2.3(\mathrm{P}<0.001)$; CFI $=0.96$; $\mathrm{GFI}=0.93$; $\mathrm{TLI}=0.94 ; \mathrm{AGFI}=0.90 ; \mathrm{NFI}=$ 
0.93; IFI $=0.96 ;$ RMSEA $=0.05$, SRMR $=0.04$ and PCLOSE is 0.05) fits the data significantly better than the common factor model, therefore suggesting that common method bias was not a major issue in this study.

\section{Results of the structural modeling analysis}

\section{Measurement model}

In order to assess whether the theory presented fits the sample data, it is important to evaluate the model fit. The two most common ways to evaluate model fit include firstly the chi-square $\left(\chi^{2}\right)$ including its degrees of freedom and $p$-value, and secondly the fit indices (Kline 2011). However, $\chi^{2}$ has appeared to be problematic because it is sensitive to sample size (Anderson and Gerbing, 1988), therefore a range of other fit indices as proposed by Hair et al. (2010) have also been used in this study, including AGFI (adjusted goodness-of-fit), CFI (comparative fit index), GFI (goodness-of-fit index), TLI (Tucker-Lewis index), NFI (normed fit index), IFI (incremental fit index), RMSEA (root mean square error of approximation) and SRMR (standardized root mean square residuals). The standardized loadings for each construct used in the measurement model are illustrated in Table III. In addition, the values of the actual and recommended values of model fit indices for this study's measurement model are presented in Table II, and indicate that all the fit indices were within the recommended range. 


\section{Table II. Fit indices for the measurement and structural model}

\begin{tabular}{llll}
\hline Fit index & Recommended value ${ }^{\mathrm{a}}$ & Measurement model & Structural model \\
\hline$\chi^{2}$ & NS at $\mathrm{p}<0.05$ & 299 & 305 \\
$\mathrm{df}$ & $\mathrm{n} / \mathrm{a}$ & 126 & 129 \\
$\chi^{2} / \mathrm{df}$ & $<5$, preferable $<3$ & 2.3 & 2.3 \\
CFI & $>0.90$ & 0.96 & 0.96 \\
GFI & $>0.90$ & 0.93 & 0.93 \\
TLI & $>0.90$ & 0.94 & 0.94 \\
AGFI & $>0.80$ & 0.90 & 0.90 \\
NFI & $>0.90$ & 0.93 & 0.93 \\
IFI & $>0.90$ & 0.96 & 0.96 \\
RMSEA & $<0.08$ & 0.05 & 0.05 \\
SRMR & $<0.10$ & 0.04 & 0.04
\end{tabular}

There is no significant reason to examine and evaluate a structural model if the constructs of the measurement model are not reliable and valid (Bagozzi and Yi, 2012; Hair et al., 2010), and thus the measurement model was evaluated for its validity and reliability. Reliability is usually assessed by examining indicator and composite reliability (Hair et al., 2010; Bagozzi and Yi, 2012). According to Bagozzi and Yi (2012), there are no universally accepted cut-off values for assessing indicator reliability and composite reliability. Values between 0.60 and 0.70 in exploratory research are considered desirable for composite reliability while in advanced research, the values should fall between 0.70 and 0.90 . An indicator that has a loading of 0.50 or above is considered reliable (Bagozzi and Yi, 2012). The results presented in Table III indicate that the measurement model is reliable.

In addition to reliability, it is also important to evaluate the model for its validity, which usually assesses both convergent and discriminant validity. Convergent validity is determined by analyzing the average variance extracted (AVE), which represents the amount of variance explained by an unobserved variable. The AVE value should be 0.50 or higher in order to achieve convergent validity. The details shown in Table III indicate that the AVE scores for all the constructs were higher than 0.50.

Finally, discriminant validity is measured by comparing the squared correlation for each pair of constructs against the AVE for each of those pair of constructs. Discriminant validity was achieved because the value 
obtained for the average variance extracted for each construct was higher than the squared correlations between the construct and all the other constructs presented in the model. This means that the AVE (Average Variance Extracted) was greater than the MSV (Maximum Shared Variance) as indicated in Table IV (Chau, 1996). 
Table III. Measurement Model Properties $(N=400)$

\begin{tabular}{llll}
\hline Constructs and Indicators & Standardized & Composite AVE \\
& loadings & Reliability
\end{tabular}

BYOD

0.59

During a regular work week, to what extent do you use a

0.60

desktop or laptop computer that you personally own for work

purposes?

During a regular work week, to what extent do you use a

smartphone or tablet or any device that you personally own for work purposes?

To what extent does your organization permit you to use

personal devices at work?

Perceived Job Autonomy

0.83

0.62

My job gives me opportunity for independence and freedom $\quad 0.80$

in how I work.

My job gives me a chance to use my personal initiative and

0.82

judgment in carrying out my work.

My job permits me to decide on my own how to go about 0.74 doing my work.

Task-Technology Fit

0.87

0.77

The technology I usually use at work is appropriate for the

0.84

tasks I perform.

The technology I usually use at work fits with the way I work. 0.92 


\begin{tabular}{lll}
\hline Constructs and Indicators & Standardized & Composite AVE \\
loadings & Reliability
\end{tabular}

\begin{tabular}{ll}
\hline I have to work very fast. & 0.62
\end{tabular}

I have too much work to do. 0.65

My workload is high. $\quad 0.88$

\begin{tabular}{lcr}
\hline Job Satisfaction & 0.76 & 0.61
\end{tabular}

Compared to other jobs, I am content with my present job. $\quad 0.81$

Generally speaking, I am satisfied with my job. $\quad 0.75$

Job Performance Self-Assessment

$0.85 \quad 0.66$

I am among the best in the company in terms of the quality of 0.78

my performance.

I am among the best in the company in terms of my 0.89

effectiveness.

I am among the best in the company in terms of my overall 0.75

performance.

Organizational Commitment

0.83

0.62

I show by my actions that I really care about the fate of this $\quad 0.77$

organization.

For me, this is the best of all possible organizations for which $\quad 0.77$

I work.

I am extremely glad to have chosen this organization to work $\quad 0.82$

for over other organizations. 
Table IV. Discriminant validity results

\begin{tabular}{|l|l|l|l|l|l|l|l|l|}
\hline & AVE & MSV & JA & BYOD & W & JP & JS & OC \\
\hline JA & 0.622 & 0.598 & 0.789 & & & & & \\
\hline BYOD & 0.586 & 0.292 & 0.507 & 0.765 & & & & \\
\hline W & 0.525 & 0.417 & 0.456 & 0.368 & 0.724 & & & \\
\hline JP & 0.656 & 0.464 & 0.601 & 0.447 & 0.578 & 0.810 & & \\
\hline JS & 0.611 & 0.598 & 0.773 & 0.435 & 0.387 & 0.567 & 0.782 & \\
\hline OC & 0.620 & 0.533 & 0.690 & 0.455 & 0.556 & 0.681 & 0.730 & 0.787 \\
\hline TTF & 0.772 & 0.546 & 0.739 & 0.540 & 0.646 & 0.636 & 0.635 & 0.713 \\
\hline
\end{tabular}

BYOD: Bring Your Own Device; TTF: Task-Technology Fit; JA: Perceived Job Autonomy; W:

Perceived Workload; JS: Job Satisfaction; JP: Job Performance; OC: Organizational Commitment.

\section{Structural model}

Once the measurement model was tested and proved to be valid, reliable, and have a good model fit, the proposed structural model presented in Figure 1 was tested and evaluated. The results of the structural model were very close to the measurement model and indicated that the model was a good fit to the data (Table II) and that the structural model was acceptable. We therefore proceeded with testing the hypothesized relationships of the proposed model.

\section{Discussion of Results}

The study developed a model containing the twelve hypotheses discussed above, which were tested using data collected from Mauritian employees. Findings provided support for 12 of the 13 proposed hypotheses as indicated in Figure 2, and the model explained 65 percent of the variance in organizational commitment. 


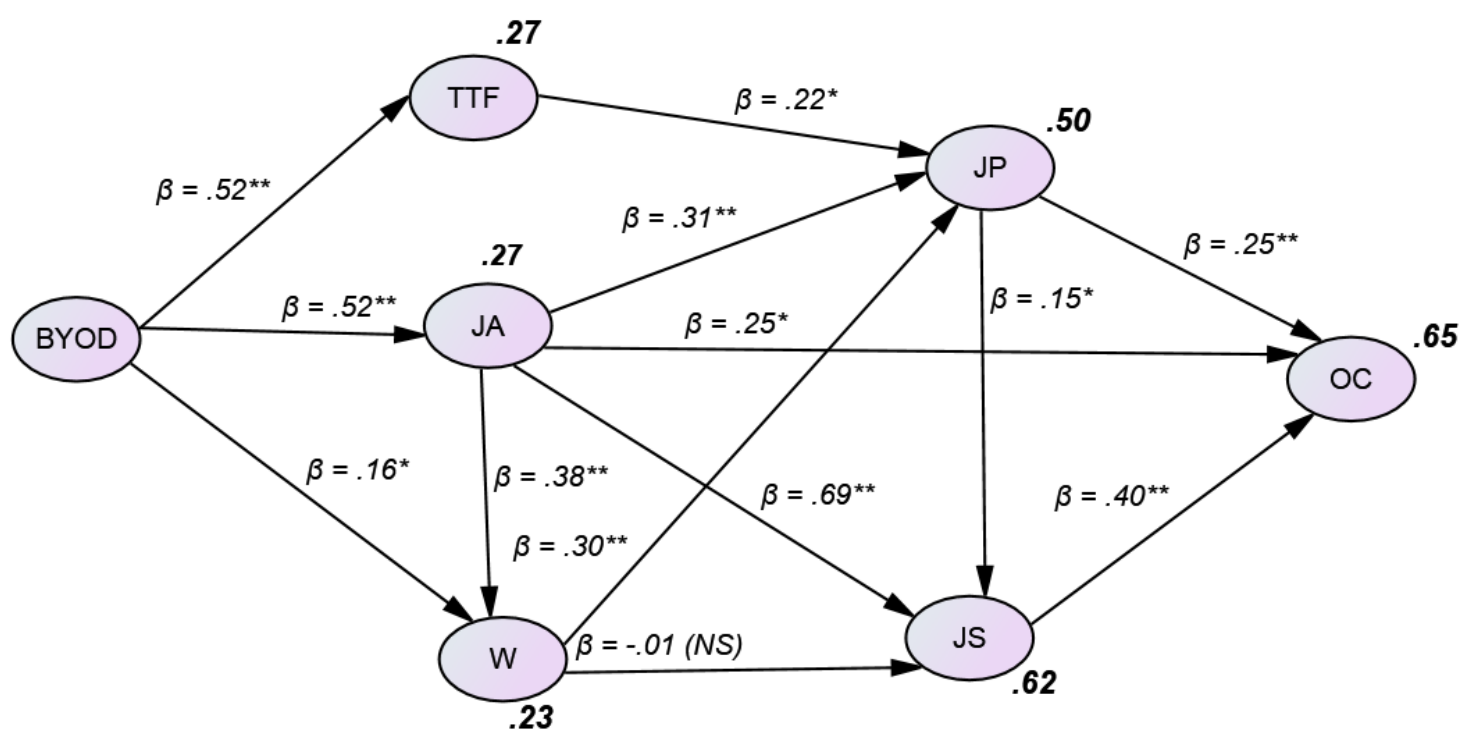

\section{Notes:}

BYOD: Bring Your Own Device; TTF: Task-Technology Fit; JA: Perceived Job Autonomy; W: Perceived Workload; JS: Job Satisfaction; JP: Job Performance Self-Assessment; OC: Organizational Commitment. $* \mathrm{p}<.01 ; * * \mathrm{p}<.001$

NS: Statistically non-significant

As shown in Table $\mathrm{V}$, the results of the path coefficient indicated that 12 of the 13 hypotheses were supported. More specifically, BYOD was found to have a significant positive influence on perceived job autonomy $(\beta=.52, p<.001, t=8.20)$, task-technology fit $(\beta=.52, p<.001, t=8.47)$ and perceived workload $(\beta=.16, p<.01, t=2.50)$, thus supporting $H 1, H 2$ and $H 3$. TTF, $(\beta=.22, p<.01, t=2.21)$, JA $(\beta=.38, p<.001, t=4.95)$ and $\mathrm{W}(\beta=.30, p<.001, t=4.09)$ in turn had a significant positive relationship with JP, while JA had a significant positive influence on $\mathrm{W}(\beta=.38, p<.001, t=4.95)$, JP $(\beta=.31, p<$ $.001, t=3.74), \mathrm{JS}(\beta=.68, p<.001, t=9.26)$ and $\mathrm{OC}(\beta=.25, p<.01, t=2.95)$. These results donate support to $H 4, H 5, H 6, H 7, H 8$ and $H 9$. JP in turn positively influenced JS $(\beta=.15, p<.01, t=2.03)$ and OC $(\beta=.25, p<.001, t=4.29)$ while JS also influenced OC $(\beta=.39, p<.001, t=4.40)$. Thus, $H 10, H 11$ and $H 12$ were supported. Finally, H13 which proposed a direct negative relationship between perceived 
workload and job satisfaction was rejected $((\beta=-0.01, t=-0.19)$. Our finding therefore contradicts those of De Cuyper and De Witte (2006), (De Alwis and Kumari, 2015) and Kunte et al. (2017), who reported a significant negative relationship between the two constructs.

Table V. Path Coefficient and their significance

\begin{tabular}{llcc}
\hline Hypothesis & Path & Path coefficient & Results \\
\hline$H 1$ & $\mathrm{BYOD} \longrightarrow \mathrm{JA}$ & $0.52^{* *}$ & Supported \\
$H 2$ & $\mathrm{BYOD} \longrightarrow \mathrm{TTF}$ & $0.52^{* *}$ & Supported \\
$H 3$ & $\mathrm{BYOD} \longrightarrow \mathrm{W}$ & $0.16^{*}$ & Supported \\
$H 4$ & $\mathrm{TTF} \longrightarrow \mathrm{JP}$ & $0.22^{*}$ & Supported \\
$H 5$ & $\mathrm{~W} \longrightarrow \mathrm{JP}$ & $0.30^{* *}$ & Supported \\
$H 6$ & $\mathrm{JA} \longrightarrow \mathrm{W}$ & $0.38^{* *}$ & Supported \\
$H 7$ & $\mathrm{JA} \longrightarrow \mathrm{JP}$ & $0.31^{* *}$ & Supported \\
$H 8$ & $\mathrm{JA} \longrightarrow \mathrm{JS}$ & $0.68^{* *}$ & Supported \\
$H 9$ & $\mathrm{JA} \longrightarrow \mathrm{OC}$ & $0.25^{* *}$ & Supported \\
$H 10$ & $\mathrm{JP} \longrightarrow \mathrm{JS}$ & $0.15^{*}$ & Supported \\
$H 11$ & $\mathrm{JP} \longrightarrow \mathrm{OC}$ & $0.25^{* *}$ & Supported \\
$H 12$ & $\mathrm{JS} \longrightarrow \mathrm{OC}$ & $0.39^{* *}$ & Supported \\
$H 13$ & $\mathrm{~W} \longrightarrow \mathrm{JS}$ & -0.01 & Rejected
\end{tabular}

Notes: $* \mathrm{p}<.01 ; * * \mathrm{p}<.001$

\section{Discussion of Results}

Our findings empirically and theoretically support the JD-R and TTF model within the BYOD context. The model proved to be a useful framework in better understanding employees' usage of BYOD and its effects on job satisfaction, performance and organizational commitment. To the best of the authors' knowledge, this is the first study to analyze, in an integrated way, the relationship between the theoretical constructs in the context of BYOD. Overall, our results showed that BYOD is well in favor of Mauritian employees. Our results also suggest that increasing the extent to which employees are able to bring their own devices leads to increases in perceived job autonomy perceived workload, and TTF. These findings suggest that employees who use their personal devices to fulfil business tasks feel more autonomous in conducting their tasks and is consistent with Morris and Venkatesh (2010), who reported that technology usage has an impact on employees' autonomy, and Niehaves et al. $(2012,2013)$ who confirmed that employees derive greater 
autonomy when utilizing their personal devices for work purposes. In addition when users are allowed to choose their own devices, they choose hardware and software that match the demands of the tasks. In other words, employees would use their own devices only if they find a fit between the devices and the tasks that they need to complete. The finding is therefore congruent with Goodhue and Thompson (1995) who suggested that the technology being used should be appropriate for an individual to conduct his tasks. The positive relationship between BYOD and perceived workload may be explained by the fact that employees perceive an increase in their workload when utilizing their personal devices for work purposes. This finding corroborates Niehaves et al. $(2012,2013)$, who confirmed that employees feel they have more work to do when using their personal devices for work purposes.

Moreover, the more employees find that their technologies are fit for completing their tasks, the more they will perform better in their job. From a theoretical perspective, these results provide support for the Tasktechnology Fit model which postulates that if the technology used is a good fit for the task being conducted, this will be accompanied by higher performance (Carswell et al., 2000; Goodhue et al., 2000; Goodhue and Thompson, 1995). This finding is congruent with Lee et al. (2007), who suggest that if there exists a fit among the technology, the task, and the user, this is more likely to promote the willingness of the user to use that technology to enhance the user's work performance.

The findings of this study solidify the belief that job demands can lead to greater job performance (Bakker et al., 2004), which in the context of this study may be explained that an increase in perceived workload is likely to result in greater performance for employees. The Job Demands-Resources model also contends that an increase in job resources can influence its job demands. In the context of this research, an increase in the job resource 'perceived job autonomy' is likely to influence the job demand 'perceived workload'. This finding suggests that perceived job autonomy helps in coping with job demands as employees are free to decide for themselves as to how and when to respond to their demands. In addition, perceived job autonomy can have a positive influence on perceived workload because of the flexibility available for the work. Despite employees having a high workload or feeling overburdened with many tasks, being autonomous allows them to make adjustments to accommodate all the tasks that they have to complete, thus offsetting negative implications of high workload. This finding corroborates with (Bakker et al., 2003).

Our findings also suggest that employees enjoy greater job performance when they are given the freedom and independence in how they conduct their work This may be explained by the fact that employees with a high sense of autonomy are likely to experience higher job satisfaction and eventually perform better in their work-related tasks while those with a low sense of autonomy are likely to experience poor performance and work exhaustion. The finding of the present research is therefore congruent with those of Dodd and 
Ganster (1996) ; Shirom et al. (2006) whose results suggest that workers who have freedom and independence in how to conduct their work are more likely to benefit from greater job performance.

The results also suggest that employees derive higher job satisfaction when they are autonomous and can decide on their own on how to go about with their work. This finding is consistent with Yeh (2015), whose results suggest that job autonomy can influence employees' job satisfaction, where employees derive higher job satisfaction when they are autonomous and can decide on their own on how to go about with their work.

Moreover, autonomous employees are more likely to be committed towards their organization. This means that employees with increasing perceived autonomy feel more dedicated towards their organization. This result corroborates the Job Demands-Resources model, and other literature, which posits that job autonomy is likely to influence employees' commitment towards their organization (Ahuja et al., 2006; Bakker et al., 2010; Park and Searcy, 2012).

The significant positive relationship between job performance and job satisfaction may be explained by the fact that the more employees perform well in their job, the higher is their job satisfaction and this finding is consistent with a long-standing body of literature (Bagozzi, 1980; Brown and Peterson, 1993; Darden et al., 1989; Judge et al., 2001; MacKenzie et al., 1998; Siegel and Bowen, 1971; Stumpf and Hartman, 1984). In addition, employees enjoy higher level of commitment towards their organization when they perform well and derive greater job satisfaction and these results corroborate (Fu and Deshpande, 2014; Petrides and Faunham, 2006).

\section{Mediating Effects}

No formal hypotheses were initially proposed for the mediating effects implied in the model of the current study. However, these were tested using the Bootstrap approach to mediation analysis (Bollen et al., 1990). Results suggested that perceived job autonomy partially mediated the relationship between job performance and organizational commitment. This is probably because employees feel committed towards their organizations when they perform well in their jobs. Thus, perceived job autonomy has a direct as well as an indirect effect (via job performance) on organizational commitment.

This study findings also suggested that perceived job autonomy partially mediated the relationship between job satisfaction and organizational commitment. This suggests that employees feel committed to their organizations when they are satisfied with their jobs. Thus, perceived job autonomy has a direct as well as an indirect effect (via job satisfaction) on organizational commitment. So far, existing research on BYOD did not empirically test job satisfaction's relationship with other variables.

Moreover, the findings obtained from this study suggested that perceived job autonomy partially mediated the relationship between perceived workload and job performance. This is probably because employees feel 
they can still perform well despite having a lot of work to do provided they perceived they are given the autonomy to conduct their tasks. Thus, perceived job autonomy has a direct as well as an indirect effect (via perceived workload) on job performance.

Results also suggested that job performance partially mediated the relationship between job satisfaction and organizational commitment. This suggest that employees feel committed to their organizations when they are satisfied with their jobs. Thus, job performance has a direct as well as indirect effect (via job satisfaction) on organizational commitment.

Furthermore, results suggested that job performance partially mediated the relationship between perceived job autonomy and job satisfaction. This is probably because employees are more satisfied with their jobs when performing well. Thus, perceived job autonomy has a direct as well as indirect effect (via job performance) on job satisfaction. So far, existing research on BYOD has treated job performance as a dependent variable (Niehaves et al., 2012; Niehaves et al., 2013).

\section{Implications}

\section{Practical implications}

Findings from the current study have significant practical implications for employers that have already incorporated, or are considering incorporating BYOD in their organizations. The results of this research confirm that BYOD has an impact on employee well-being (through job satisfaction), performance and organizational commitment. These results are consistent with those of previous research and empirical studies based on job demands-resources model and task-technology fit model in showing that employees with appropriate levels of autonomy, workload and task-technology fit enjoy greater performance, satisfaction and higher commitment. These findings therefore suggest that employees who utilize their personal mobile devices to fulfil business tasks do contribute to their well-being, performance and commitment. Thus, this study contributes to the growing body of evidence that organizations should consider allowing their employees to utilize their personal devices for work purposes. Subsequently, employers may wish to consider incorporating BYOD programs for new recruits. Besides concerns about data security, adopting BYOD is ultimately good for organizations since this trend could result in employees being more committed to their organizations, who derive greater job satisfaction and who achieve higher job performance. These results also suggest that the JD-R model could usefully be elaborated upon to explicitly include BYOD while investigating employee well-being, performance and commitment. With regards to organizational commitment, organizations intending to seek and maintain a long-term relationship with employees are likely to benefit in financial terms through greater performance, more satisfied and highly committed employees. 


\section{Theoretical implications}

From a theoretical point of view, this study contributes to the BYOD, job demands-resources model, job satisfaction, job performance and organizational commitment literature. The literature search process of the current study indicates that little has yet been published on theory development with regards to BYOD. The present study therefore may be a starting point for future theory development in this area. This study is also one of the first to examine, in an integrated way, the relationship between the theoretical constructs presented in our research model. Moreover, our research demonstrates that people as well as procedures are highly affected by the BYOD trend. This is not surprising because BYOD has been triggered by consumers and their individual needs, and demonstrates that Information Systems research in the context of BYOD should have an interdisciplinary focus. Hence, it is important to consider psychological aspects when developing a theoretical perspective on BYOD and its implications.

\section{Conclusion}

This study tested a model with thirteen hypotheses. The model was based on the JD-R theory and the TaskTechnology Fit model, and examined the impact of BYOD on job performance, job satisfaction and organizational commitment, and was tested using structural equation modelling. Data was collected from Mauritian employees.

\section{Contribution}

The most notable theoretical contribution of the study is the use of the JD-R theory as well as the TaskTechnology Fit model to explain the impact of BYOD on employees. While previous research has considered the impact of BYOD on job performance (Niehaves et al., 2012; Köffer et al., 2014), to the best of our knowledge, no previous BYOD studies used these theoretical lenses.

Existing BYOD models in the literature have also not considered the role of organizational commitment and to our knowledge, no prior studies of BYOD have investigated its impact on organizational commitment; our findings confirm that BYOD has a positive impact on organizational commitment. In addition, the study also identifies job performance as a mediating variable.

A further theoretical contribution of this study is that it adds to the flexibility of the JD-R theory by expanding the model to explain employee well-being (through job satisfaction), job performance and organizational commitment. No prior model has used these constructs in an integrated theoretical framework to determine the impact that BYOD has on these outcomes. Future research could expand the scope of this study by also investigating the effect of BYOD on burnout and exhaustion. 


\section{Limitations and future research}

While this study has the same methodological limitations that affect any study employing self-reported survey data, the JD-R theory that forms the theoretical basis of the research supports both self-report and observer ratings. Indeed, the JD-R authors themselves believe that "a distinct feature of the results of our study is the support for the JD-R model for both self-reports and observer ratings" (Demerouti et al., 2001 p. 509). Although, as noted by Demerouti et al. (2001), there might be some variance between self-reported and observer-reported ratings, where the constructs relate to workers' perceptions as they do in this study, self-reported variables are acceptable. Nevertheless, we advise the same caution in interpreting these results as in any other, methodologically similar study.

While this research has provided new insights into the relationships between BYOD and well-being, performance and commitment, some limitations need to be acknowledged. The study was conducted with Mauritian employees, and its findings may have limited applicability to other countries. Further research can be conducted in other locations to ensure generalizability of results. Nevertheless, employers from other countries may conduct similar or related studies to further investigate the reciprocal causality between BYOD and employee well-being, performance and organizational commitment. The proposed model contained only one job demand and one job resource, and it is therefore recommended to identify and incorporate other relevant job demands and resources while testing the model.

On the basis of the tested research model presented in this study, the authors are currently undertaking a follow-up qualitative study to more deeply explore the relationships among the variables and subsequently, getting deeper insights into the causal relationships and why they exist. This will provide a more comprehensive understanding of the BYOD trend and the consequences of its adoption, particularly in relation to employee well-being, performance and organizational commitment.

Since the JD-R model is motivational in nature, this study ignored work motivation as a construct, but it is plausible that BYOD has impacts on employee motivation; further research in this direction is suggested, as it will be important to understand the impact BYOD has on employee motivation as it becomes increasingly widespread. This step will contribute to solve the discrepancies still prevailing between theory and practitioner studies. This will in turn enable organizations to take advantage from the full performancemotivation potential of BYOD despite security concerns.

Finally, there has been little theory development relating to BYOD so far, and the theoretical model developed in this study is thus a starting point for future theoretical development. 


\section{References}

Ahuja, B. M. K. and Thatcher, J. B. (2005) 'Moving beyond intentions and toward the theory of trying: Effects of work environment and gender on post-adoption Informational Technology use', MIS Quarterly, 29(3), pp. 427-459.

Ahuja, M. K., Chudoba, K. M., Kacmar, C. J., Mcknight, D. H. and George, J. F. (2006) 'IT Road Warriors: Balancing Work-Family conflict, Job Autonomy, and Work Overload to Mitigate Turnover Intentions', MIS Quarterly, 30(3), pp. 1-18.

Ahuja, M. K., Chudoba, K. M., Kacmar, C. J., Mcknight, D. H. and George, J. F. (2007) 'IT road warriors: Balancing work-family conflict, job autonomy, and work overload to mitigate turnover intentions', MIS Quartely, 31(1), pp. 1-17.

Allen, N. J. and Meyer, J. P. (1990) 'The measurement and antecedents of affective, continuance and normative commitment to the organization', Journal of Occupational Psychology, 63, pp. 1-18.

De Alwis, C. A. and Kumari, M. H. (2015) 'The Nursing Shortage Impact on Job Outcome (The Case in Sri Lanka)', Journal of Competitiveness, 7(3), pp. 75-94. doi: 10.7441/joc.2015.03.06.

Anderson, J. C. and Gerbing, D. W. (1988) 'Structural equation modeling in practice: A review and recommended two-step approach.’, Psychology Bulletin, 1033(3), pp. 411-423.

Bagozzi (1980) 'Satisfaction in an Industrial Sales Force: An Examination of Their Antecedents and Simulaneity', Journal of Marketing, 44, pp. 65-77.

Bagozzi, R. P. and Yi, Y. (2012) 'Specification, evaluation, and interpretation of structural equation models', Journal of the Academy of Marketing Science, 40(1), pp. 8-34.

Bakker, A. B., Boyd, C. M., Dollard, M., Gillespie, N., Winefield, A. H. and Stough, C. (2010) 'The role of personality in the job demands- resources model', Career Development International, 15(7), pp. 622636.

Bakker, A. B. and Demerouti, E. (2007) 'The Job Demands- Resources model: state of the art', Journal of Managerial Psychology, 22(3), pp. 309-328.

Bakker, A. B. and Demerouti, E. (2008) 'Towards a model of work engagement', Career Development International, 13(3), pp. 209-223. doi: 10.1108/13620430810870476.

Bakker, A. B. and Demerouti, E. (2014) 'Job Demands-Resources Theory’, Wellbeing, III, pp. 1-28.

Bakker, A. B., Demerouti, E., Taris, T. W., Schaufeli, W. B. and Schreurs, P. J. G. (2003) 'A multigroup analysis of the job demands-resources model in four home care organizations.', International Journal of Stress Management, 10(1), pp. 16-38.

Bakker, A. B., Demerouti, E. and Verbeke, W. (2004) 'Using the Job Demands-Resources Model to predict burnout and performance', Human Resource Management, 42(3), pp. 271-288.

Bakker, A. B., Hakanen, J. J., Demerouti, E. and Xanthopoulou, D. (2007) 'Job resources boost work engagement, particularly when job demands are high.', Journal of Educational Psychology, 99(2), pp. 274-284.

Bakker, A. B., Veldhoven, M. V. and Xanthopoulou, D. (2010) 'Beyond the Demand-Control Model: Thriving on High Job Demands and Resources', Journal of Personnel Psychology, 9(1), pp. 3-16.

Benbasat, I. and Barki, H. (2007) 'Quo vadis, TAM?', Journal of the Association for Information Systems, 8(4), pp. 211-218. 
Bollen, K. A., Stine, R. and Stinet, R. (1990) 'Direct and Indirect Effects: Classical and Bootstrap Estimates of Variability', Source: Sociological Methodology, pp. 115-140.

Boyd, C. M., Bakker, A. B., Pignata, S., Winefield, A. H., Gillespie, N. and Stough, C. (2011) 'A Longitudinal Test of the Job Demands-Resources Model among Australian University Academics', Applied Psychology: An international Review, 60(1), pp. 112-140.

Brown, A. E. and Grant, G. G. (2005) 'Framing the Frameworks : A Review of IT Governance Research', Communications of the Association for Information Systems, 15(38), pp. 696-712.

Brown, S. P. and Peterson, R. A. (1993) 'Antecedents and Consequences of Salesperson Job Satisfaction: Meta-Analysis and Assessment of Causal Effects', Journal of Marketing Research, 30(1), p. 63.

Carswell, L., Thomas, P., Petre, M., Price, B. and Richards, M. (2000) 'Distance education via the Internet: the student experience', British Journal of Educational Technology, 31(1), pp. 29-46.

Chau, P. Y. K. (1996) 'An Empirical Assessment of a Modified Technology Acceptance Model', Journal of Management Information Systems, 13(2), pp. 185-204.

Chou, P. N., Chang, C. C. and Lin, C. H. (2017) 'BYOD or not: A comparison of two assessment strategies for student learning', Computers in Human Behavior. Elsevier Ltd, 74, pp. 63-71. doi: 10.1016/j.chb.2017.04.024.

Clausen, T. and Borg, V. (2011) 'Job demands, job resources and meaning at work', Journal of Managerial Psychology, 26(8), pp. 665-681.

Darden, W. R., Hampton, R. and Howell, R. D. (1989) 'Career versus organizational commitment: Antecedents and consequences of retail salespeople's commitment', Journal of Retailing, 65, pp. 80-105.

De Alwis, C. A. and Kumari, M. H. (2015) 'The Nursing Shortage Impact on Job Outcome (The Case in Sri Lanka)', Journal of Competitiveness, 7(3), pp. 75-94. doi: 10.7441/joc.2015.03.06.

Deci, E. L. and Ryan, R. M. (1985) Intrinsic motivation and self-determination in human behavior. New York: Plenum Press.

De Cuyper, N. and De Witte, H. (2006) 'Autonomy and workload among temporary workers: Their effects on job satisfaction, organizational commitment, life satisfaction, and self-rated performance', International Journal of Stress Management, 13(4), pp. 441-459. doi: 10.1037/1072-5245.13.4.441.

Demerouti, E., Bakker, A. B., Nachreiner, F. and Schaufeli, W. B. (2001) 'The job demands-resources model of burnout.', Journal of Applied Psychology, 86(3), pp. 499-512.

DeVaro, J., Li, R. and Brookshire, D. (2007) 'Analysing the job characteristics model: new support from a cross-section of establishments', The International Journal of Human Resource Management, 18(June), pp. 986-1003.

Disterer, G. and Kleiner, C. (2013) 'BYOD Bring Your Own Device', Procedia Technology. Elsevier B.V., 9, pp. 43-53. doi: 10.1016/j.protcy.2013.12.005.

Dodd, N. G. and Ganster, D. C. (1996) 'The interactive effects of variety, autonomy, and feedback on attitudes and performance', Journal of Organizational Behavior, 17, pp. 329-347.

Eby, L. T., Freeman, D. M., Rush, M. C. and Lance, C. E. (1999) 'Motivational bases of affective organizational commitment: A partial test of an integrative theoretical model', Journal of Occupational and Organizational Psychology, 72, pp. 463-483.

Eslahi, M., Naseri, M. V., Hashim, H., Tahir, N. M. and Saad, E. H. M. (2014) 'BYOD: Current state and security challenges', ISCAIE 2014 - 2014 IEEE Symposium on Computer Applications and Industrial 
Electronics, (April), pp. 189-192. doi: 10.1109/ISCAIE.2014.7010235.

Farrell, D. and Stamm, C. L. (1988) 'Meta-Analysis of the Correlates of Employee Absence', Human Relations, 41(3), pp. 211-227.

Fast, N. J., Burris, E. R. and Bartel, C. A. (2014) 'Managing to stay in the dark: Managerial self-efficacy, ego defensiveness, and the aversion to employee voice', Academy of Management Journal, 57(4), pp. 1013-1034.

Fu, W. and Deshpande, S. P. (2014) 'The Impact of Caring Climate, Job Satisfaction, and Organizational Commitment on Job Performance of Employees in a China???s Insurance Company', Journal of Business Ethics, 124(2), pp. 339-349.

Gaertner, S. (2000) 'Structural Determinants of Job Satisfaction and Organizational Commitment in Turnover Models', Human Resource Management Review, 9(4), pp. 479-493.

Gebauer, J. and Ginsburg, M. (2009) 'Exploring the black box of task-technology fit', Communications of the ACM, 52(1), pp. 130-135. doi: 10.1145/1435417.1435447.

Goodhue, D. L., Klein, B. D. and March, S. T. (2000) 'User Evaluations of IS as Surrogates for Objective Performance', Information \& Management, 38(2), pp. 87-101.

Goodhue, D. L. and Thompson, R. L. (1995) 'Task-Technology Fit and Individual Performance', MIS Quarterly, 19(2), pp. 213-236.

Hackman, J. R. and Oldham, G. R. (1976) 'Motivation through the design of work: test of a theory', Organizational Behavior and Human Performance, 16(2), pp. 250-279.

Hackman, J. R., Pearce, J. L. and Wolfe, J. C. (1978) 'Effects of changes in job characteristics on work attitudes and behaviors: A naturally-occurring quasi-experiment', Organizational Behavior and Human Performance, 21, pp. 289-304.

Hackman, R. J. and Oldham, G. R. (1980) Work Redesign. Reading MA: Addison-Wesley.

Hair, J. F., Black, W. C., Babin, B. B. and Anderson, R. E. (2010) Multivariate Data Analysis. Seventh Ed. Pearson Prentice Hall.

Hakanen, J. J., Bakker, A. B. and Demerouti, E. (2005) 'How dentists cope with their job demands and stay engaged: The moderating role of job resources', European Journal of Oral Sciences, 113(6), pp. 479-487.

Harris, J., Ives, B. and Junglas, I. (2012) 'IT Consumerization: When Gadgets Turn Into Enterprise IT Tools', MIS Quarterly Executive, 11(3), pp. 99-112.

Hudson, D. and Grant, G. (2013) 'A Theory of the Firm Perspective on Entrepreneurial Use of Consumer IT as Corporate IT', Association for Information Systems: International Conference on Information Resources Management.

Iverson, R. D. and Roy, P. (1994) 'A Causal Model of Behavioral Commitment: Evidence From a Study of Australian Blue-collar Employees’, Journal of Management, 20(1), pp. 15-41.

Judge, T. A., Thoresen, C. J., Bono, J. E. and Patton, G. K. (2001) 'The Job Satisfaction-Job Performance Relationship: A Qualitative and Quantitative Review', Psychological Bulletin, 127(3), pp. 376-407.

Junglas, I. A. and Watson, R. T. (2008) 'Location-Based Services', Communications of the ACM, 51(3), pp. 65-69. doi: 10.1002/0470092335.

Keaveney, S. M. and Nelson, J. E. (1993) 'Coping with organizational role stress: Intrinsic motivational 
orientation, perceived role benefits, and psychological withdrawal', Journal of the Academy of Marketing Science, 21(2), pp. 113-124.

Kemp, N. J. and Cook, J. D. (1983) 'Job longevity and growth need strength as joint moderators of the task design-job satisfaction relationship', Human Relations, 36(10), pp. 883-898.

Kim, S. S. and Malhotra, N. K. (2005) 'Ecompanion: A Longitudinal Model of Continued IS Use', Management Science, 51(5), pp. 741-755.

Klein, H. J., Molloy, J. C. and Brinsfield, C. T. (2012) 'Reconceptualizing workplace commitment to redress a stretched construct: Revisiting assumptions and removing confounds', Academy of Management Journal, 37(1), pp. 130-151.

Kline, R. B. (2011) Principles and practice of structural equation modeling. Edited by Third. London and New York: The Guildford Press.

Köffer, S., Ortbach, K. C. and Niehaves, B. (2014) 'Exploring the Relationship between IT Consumerization and Job Performance', Communications of the Association for Information Systems, $35(1)$.

Köffer, S., Ortbach, K., Junglas, I., Niehaves, B. and Harris, J. (2015) 'Innovation through BYOD? The Influence of IT Consumerization on Individual IT Innovation Behavior', Business and Information Systems Engineering, 57.

Krishnan, B. C., Netemeyer, R. G. and Boles, J. S. (2002) 'Self-Efficacy, Competitiveness, and Effort as Antecedents of Salesperson Performance', Journal of Personal Selling \& Sales Management, 22(4), pp. 285-295.

Kunte, M., Gupta, P., Bhattacharya, S. and Neelam, N. (2017) 'Role overload, role self distance, role stagnation as determinants of job satisfaction and turnover intention in banking sector', Indian Journal of Psychological Medicine, 39(5), p. 590. doi: 10.4103/0253-7176.217022.

Langelaan, S., Bakker, A. B., Doornen, L. J. P. and Schaufeli, W. B. (2006) 'Burnout and work engagement: Do individual differences make a difference?', Personality and Individual Differences, 40(3), pp. 521-532.

Larsen, T. J., Sørebø, A. M. and Sørebø, Ø. (2009) 'The role of task-technology fit as users' motivation to continue information system use', Computers in Human Behavior. Elsevier Ltd, 25(3), pp. 778-784.

Lawler, E. E. and Porter, L. W. (1967) 'The effect of performance on job satisfaction', Industrial Relations, 7(1), pp. 20-28.

Leclercq - Vandelannoitte, A. (2015) 'Managing BYOD: how do organizations incorporate user-driven IT innovations?', Information Technology \& People, 28(1), pp. 2-33.

Lee, C. C., Cheng, H. K. and Cheng, H. H. (2007) 'An empirical study of mobile commerce in insurance industry: Task-technology fit and individual differences’, Decision Support Systems, 43(1), pp. 95-110.

Lee, R. T. and Ashforth, B. E. (1996) 'A meta-analytic examination of the correlates of the three dimensions of job burnout.', The Journal of Applied Psychology, 81(2), pp. 123-133.

Lin, T. C. and Huang, C. C. (2008) 'Understanding knowledge management system usage antecedents: An integration of social cognitive theory and task technology fit', Information and Management, 45(6), pp. $410-417$.

Locke, E. A. (1970) 'Job satisfaction and job performance: a theoretical analysis.', Organisational Behaviour and Human Performance, 5(5), pp. 484-500. 
MacKenzie, S. B., Podsakoff, P. M. and Ahearne, M. (1998) 'Some Possible Antecedents and Consequences of In-Role and Extra-Role Salesperson Performance', Journal of Marketing, 62(3), p. 87.

Mathieu, J. E. and Zajac, D. M. (1990) 'A review and meta analysis of the antecendents, correlates, and consequences of organizational commitment', Psychological Bulletin, 108(2), pp. 171-194. doi: 10.1037/0033-2909.108.2.171.

McGregor, A., Magee, C. A., Caputi, P. and Iverson, D. (2016) 'A job demands-resources approach to presenteeism', Career Development International, 21(4), pp. 402-418. doi: 10.1108/CDI-01-2016-0002.

McKnight, D. H., Phillips, B. and Hardgrave, B. C. (2009) 'Which reduces IT turnover intention the most: Workplace characteristics or job characteristics?', Information and Management, 46(3), pp. 167174.

Michaels, C. E. and Spector, P. E. (1982) 'Causes of Employee Turnover: A Test of the Mobley, Griffeth, Hand, and Meglino Model', Journal of Applied Psychology, 67(1), pp. 53-59. doi: 10.1037/0021-9010.67.1.53.

Moore, J. E. (2000) 'One road to turnover: An examination of work exhaustion in technology professionals', MIS Quarterly, 24(1), pp. 141-168.

Morris, M. G. and Venkatesh, V. (2010) 'Job characteristics and job satisfaction: Understanding the role of Enterprise Resource Planning System implementation’, MIS Quarterly, 34(1), pp. 143-161.

Moschella, D., Neal, D., Opperman, P. and Taylor, J. (2004) 'The Consumerization of Information Technology. El Segundo. CSC Research White Paper’. El Segundo.

Motowildo, S. J., Borman, W. C. and Schmit, M. J. (1997) 'A theory of individual differences in task and contextual Performance', Human Performance, 10(2), pp. 71-83.

Mowday, R. T. ., Porter, L. W. . and Steers, R. M. . (1982) Employee-Organization linkages: The psychology of commitment, absenteeism, and turnover. vol 153. New York: Academic Press. doi: $10.2307 / 2068333$.

Mowday, R. T., Steers, R. M. and Porter, L. W. (1979) 'The Measurement of Organizational Commitment', Journal of Vocational Behavior, 14, pp. 224-247. doi: 10.1080/00224545.1996.9714004.

Naderi Anari, N. (2012) 'Teachers: emotional intelligence, job satisfaction, and organizational commitment', Journal of Workplace Learning, 24(4), pp. 256-269.

Niehaves, B., Koeffer, S., Ortbach, K. and Stefan, K. (2012) 'Towards an IT Consumerization Theory-A Theory and Practice Review', in Working Papers, ERCIS - European Research Center for Information Systems, pp. 1-34.

Niehaves, B., Köffer, S. and Ortbach, K. (2013) 'The effect of private IT use on work performanceTowards an IT Consumerization Theory', 11th International Conference on Wirtschaftsinformatik, (March), pp. 39-53.

Ortbach, K. (2015) 'Unraveling the effect of personal innovativeness on Bring-Your-Own-Device (BYOD) intention - The role of perceptions towards enterprise-provided and privately - 2 related work.', Twenty-third European Conference on Information Systems (ECIS), pp. 1-17.

Ortbach, K., Bode, M., Koeffer, S. and Niehaves, B. (2013) 'Individualization of Information Systems Analyzing antecedents of IT', Proceedings of the 19th Americas Conference on Information Systems (AMCIS), Chicago, USA., pp. 1-18.

Ortbach, K., Brockmann, T. and Stieglitz, S. (2014) 'Drivers for the Adoption of Mobile Device 
Management in Organizations', Twenty Second European Conference on Information Systems, (Mdm), pp. 1-18.

Ortbach, K., Köffer, S., Müller, C. P. F. and Niehaves, B. (2013) 'How IT Consumerization Affects the Stress Level at Work: A Public Sector Case Study', PACIS 2013 Proceedings.

Park, R. and Searcy, D. (2012) 'Job Autonomy as a Predictor of Mental Well-Being: The Moderating Role of Quality-Competitive Environment', Journal of Business and Psychology, 27(3), pp. 305-316.

Parker, S. K., Wall, T. D. and Cordery, J. L. (2001) 'Future work design research and practice : Towards an elaborated model of work design', Journal of Occupational and Organizational Psychology, 74, pp. 413-440.

Petrides, K. V. and Faunham, A. (2006) 'The role of trait emotional intelligence in a gender-specific model of organizational ariables', Journal of Applied Psychology, 36(2), pp. 552-569.

Podsakoff, P. M., MacKenzie, S. B., Lee, J.-Y. and Podsakoff, N. P. (2003) 'Common method biases in behavioral research: A critical review of the literature and recommended remedies.', Journal of Applied Psychology, 88(5), pp. 879-903. doi: 10.1037/0021-9010.88.5.879.

Rotundo, M. and Sackett, P. R. (2002) 'The relative importance of task, citizenship, and counterproductive performance to global ratings of job performance: A policy-capturing approach', Journal of Applied Psychology, 87(1), pp. 66-80.

Schaufeli, W. B. and Bakker, A. B. (2004) 'Job Demands and Job Resources and Their Relationship with Burnout and Engagement: A Multiple-Sample Study relationship with burnout and', Journal of Organizational Behavior, 25, pp. 293-315.

Schaufeli, W. B. and Taris, T. W. (2014) 'Bridging occupational, organizational and public health: A transdisciplinary approach', Bridging Occupational, Organizational and Public Health: A Transdisciplinary Approach, 9789400756, pp. 1-249.

Seigneur, J., Kölndorfer, P., Busch, M. and Hochleitner, C. (2013) 'Conference Proceedings A Survey of Trust and Risk Metrics for a BYOD Mobile Worker World', in Third International Conference on Social Eco-Informatics, pp. 217-228.

Shirom, A., Nirel, N. and Vinokur, A. D. (2006) 'Overload, autonomy, and burnout as predictors of physicians' quality of care.', Journal of Occupational Health Psychology, 11(4), pp. 328-342.

Siegel, J. and Bowen, D. (1971) 'Satisfaction and performance: Causal relationships and moderating effects', Journal of Vocational Behavior, pp. 263-269.

Spector, P. E. (1986) 'Perceived Control by Employees: A Meta-Analysis of Studies Concerning Autonomy and Participation at Work', Human Relations, pp. 1005-1016.

Steelman, Z. R., Lacity, M. and Sabherwal, R. (2016) 'Charting Your Organization' s Bring-Your- OwnDevice Voyage’, MIS Quartely, 2016(June), pp. 85-104.

Stumpf, S. A. and Hartman, K. (1984) 'Individual Exploration to Organizational Commitment or Withdrawal.', Academy of Management Journal, 27(2), pp. 308-329.

Taegoo, K., Suh, Y. K., Lee, G. and Choi, B. G. (2010) 'Modelling roles of Task-Technology Fit and self-efficacy in Hotel employees' usage behaviours of Hotel Information Systems', International Journal of Tourism Research, 12, pp. 709-725.

Tarhini, A., El-Masri, M., Ali, M. and Serrano, A. (2016) 'Extending the UTAUT model to understand the customers' acceptance and use of internet banking in Lebanon', Information Technology \& People, 
29(4), pp. 830-849. doi: 10.1108/ITP-02-2014-0034.

Tett, R. P. and Meyer, J. P. (1993) 'Job Satisfaction, Organizational Commitment, Turnover Intention, and Turnover: Path Analyses Based on Meta- Analytic Findings', Personnel Psychology, 46(2), pp. 259293. doi: 10.1111/j.1744-6570.1993.tb00874.x.

Tripp, J. F., Riemenschneider, C. and Thatcher, J. B. (2016) 'Development as Work Redesign', Journal of the association for Information systems, 17(4), pp. 267-307.

Tsui, A. S., Pearce, J. L. and Porter, L. W. (1997) 'Employee-Organization Relationship : Does Investment in Employees Pay Oef?', 40(5), pp. 1089-1122.

Umstot, D. D., Bell, C. H. and Mitchell, T. R. (1976) 'Effects of job enrichment and task goals on satisfaction and productivity: Implications for job design.', Journal of Applied Psychology, 61(4), pp. 379-394.

Venkatesh, V., Morris, M. G., Davis, F. D. and Davis, G. B. (2003) 'User Acceptance of Information Technology: Toward a Unified View', MIS Quarterly, 27(3), pp. 425-478.

Wall, T. D., Kemp, N. J., Jackson, P. R. and Clegg, C. W. (1986) 'Outcomes of autonomous workgroups: a long-term field experiment', Academy of Management Journal, pp. 280-304.

Wallace, J. E. (1995) 'Corporatist control and organizational commitment among Professionals: The case of lawyers working in law firms', Social Forces, 73(3), pp. 811-839.

Weeger, A., Wang, X. and Gewald, H. (2015) 'IT Consumerization: BYOD-Program Acceptance and its Impact on Employer Attractiveness', The Journal of Computer Information Systems, 56(1), pp. 1-10. doi: 10.1080/08874417.2015.11645795.

Weiß, F. and Leimeister, J. M. (2012) 'Consumerization: IT innovations from the consumer market as a challenge for corporate IT', Business and Information Systems Engineering, 4(6), pp. 363-366. doi: 10.1007/s12599-012-0234-4.

Xanthopoulou, D., Bakker, A. B., Demerouti, E. and Schaufeli, W. B. (2007) 'The role of personal resources in the job demands-resources model.', International Journal of Stress Management, 14(2), pp. 121-141.

Yeh, H.J. (2015) 'Job Demands, Job Resources, and Job Satisfaction in East Asia', Social Indicators Research, 121(1), pp. 47-60. 